\title{
COPPER MATERIALS SYSTEM FOR MICROCIRCUITRY: A STATUS REPORT
}

\author{
J. D. MITCHELL, P. C. DONOHUE, C. R. NEEDES, R. E. FUNER and R. O. UHLER \\ E. I. du Pont de Nemours and Company, Incorporated Photo Products Department, Electronic Materials \\ Division, Wilmington, Delaware 19898
}

\begin{abstract}
The electronics industry has become interested in a thick film materials system based on copper for both technical and economic reasons. Copper conductors offer excellent conductivity, solderability, and solder leach resistance as well as lower intrinsic metal cost and price stability.

Significant adoption of copper in thick film applications requires a complete system of materials for the designer and manufacturer to choose from and sufficient processing information to assist the industry to get started. Industry has begun the adoption of copper in selected applications. Design of new applications and experience in processing will move this technology forward in the industry.

$\mathrm{Du}$ Pont has developed a copper materials system which includes copper conductor compositions, low $\mathrm{K}$ dielectric and compatible resistor compositions. The compositions are screen printed, dried in an air atmosphere at $120^{\circ} \mathrm{C}$ for ten minutes and fired in a nitrogen atmosphere to a peak temperature of $900^{\circ} \mathrm{C}$. All materials in the copper system may be processed in commercially available atmosphere conveyor furnaces using commercial nitrogen.

The copper compositions provide high adhesion conductors with resistivity values in the range of one to two milliohms per square. They can be used to make multilayer interconnect structures, microwave circuits, and as a replacement for Mo-Mn metallizing. In addition, copper may be used as the conductor on porcelain-enamelled steel substrates. The dielectric composition provides a dense film with a dielectric constant of about eight which can be used with copper to make multilayer interconnect structures. The resistor compositions produce resistors with temperature coefficient of resistance (TCR) less than $150 \mathrm{ppm}$ per ${ }^{\circ} \mathrm{C}$ and are useful for resistor networks and hybrid microcircuits.
\end{abstract}

\section{INTRODUCTION}

Industry interest in a thick film materials system based on copper has increased in the latter part of the 1970's for both technical and economic reasons. As a thick film conductor, copper offers excellent conductivity, solderability and solder leach resistance relative to silver-bearing conductors. In addition a copper conductor offers price stability and, with adoption in higher volumes, will offer lower material costs to microcircuit manufacturers than silver-bearing conductors.

Significant adoption of copper in thick film applications requires a complete system of materials including resistors and higher $\mathrm{K}$ dielectrics for printed capacitors. Since compositions of the copper materials system are fired in nitrogen, sufficient processing information to help the industry get started is also needed. Industry has begun the adoption of copper in selected applications. Design of new applications and experience in processing will be required to move this technology forward in the industry.

Du Pont has a commercial copper conductor and compatible low $\mathrm{K}$ dielectric compositions and an initial resistor system available. In addition, significant pro- cessing studies in the nitrogen firing area have been completed. This paper is a status report with particular emphasis on potential applications for copper, the resistor properties and recently developed processing information.

\section{PRODUCTS AVAILABLE}

Four different copper compositions have been developed for fired thick film applications on alumina and beryllia substrates. 9922 is a high adhesion, low resistance conductor used for resistor terminations and microwave applications. 9923 is compatible with nitrogen-fireable dielectric and was developed for multilayer circuit applications. 9924 is similar to 9923 but produces thinner fired films which facilitates printing high resolution dielectric patterns over the copper. 4234 was designed for printing through holes to connect one side of a substrate with the other.

Dielectric composition 4175 was developed for use with copper to make multilayer structures. It is fireable in nitrogen and has a dielectric constant of about eight.

A nitrogen-fireable resistor series was designed to be 
compatible with 9922 copper and is processable under the same conditions. The series is based on new nonnoble metal technology and presently consists of compositions with resistivities of $10,100,1000$, and 10,000 ohms per square. Corresponding product numbers are 4239, 4238, 4237 and 4299. The nitrogen-fireable resistor compositions are similar in properties to the 1600 series $\mathrm{BIROX}^{\circledR}$ compositions.

Products under development are a lower-loss microwave copper composition for alumina and a $100 \mathrm{~K}$ ohm per square resistor composition to extend the range of the nitrogen-fireable series. Additional products being developed are copper, dielectric and resistor compositions suitable for firing at $625^{\circ} \mathrm{C}$ on porcelain-enamelled steel.

\section{PROCESSING COPPER COMPOSITIONS}

The copper compositions are printed with 325-mesh stainless steel screen to produce fired films which are about 15 micrometers thick. The prints are dried about 10 minutes at $120^{\circ} \mathrm{C}$ in an air atmosphere using either convection or infrared driers. To avoid oxidizing the copper the drying temperature should not exceed $150^{\circ} \mathrm{C}$. Infra-red ovens must be adjusted carefully; when subjected to direct radiation, the surface of the copper may reach higher temperatures than indicated by the oven controller, resulting in oxidation of the copper. Dried copper films which are oxidized will produce grey or purple fired films which are difficult to solder.

Copper is fired in a nitrogen atmosphere in a thick film conveyor furnace similar to those shown in Figure 1. Commercially available furnaces may be used. The typical temperature profile shown in Figure 2 is about
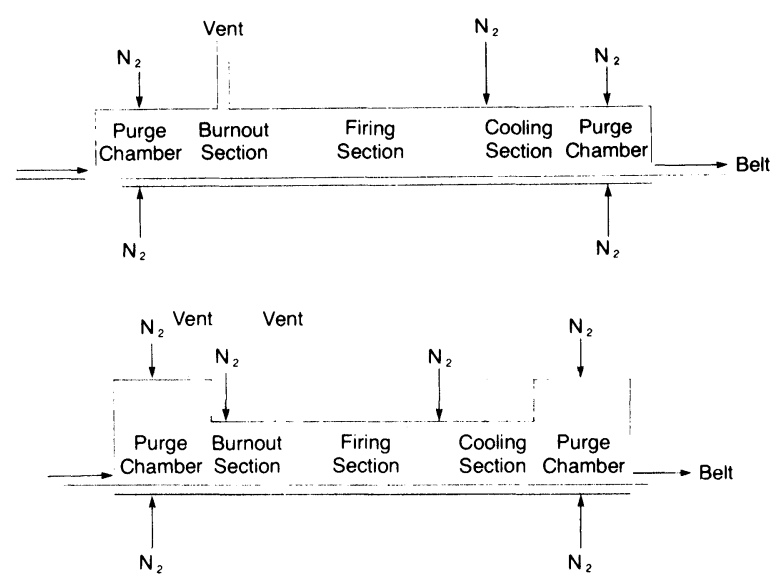

FIGURE 1 Two nitrogen furnace designs.
55 minutes long and holds at a peak temperature of $900^{\circ} \mathrm{C}$ for $6-10$ minutes. Time and temperature may be varied. Copper has been successfully fired in profiles as short as 20 minutes and at peak temperatures as high as $950^{\circ} \mathrm{C}$ and as low as $850^{\circ} \mathrm{C}$. During firing of dried copper films, the oxygen concentration in the hot sections of the furnace should be maintained below 15 to $20 \mathrm{ppm}$ to avoid oxidizing the copper. Oxygen concentration of 6-8 ppm in the burnout section has been found satisfactory for firing copper. When properly processed, fired thick film copper is moderately reflective and copper-pink in color.

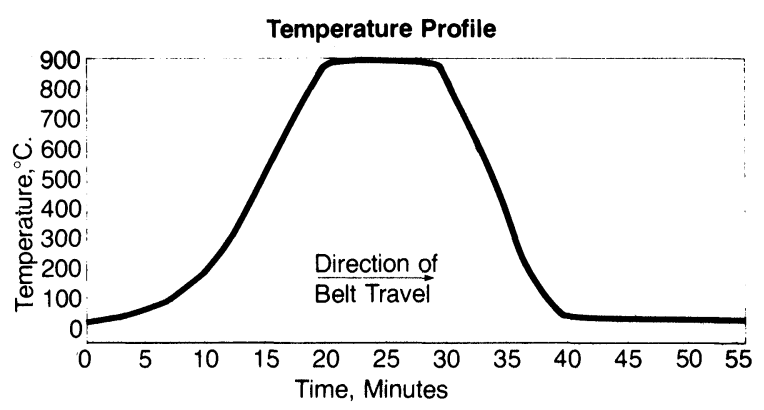

FIGURE 2 Nitrogen furnace.

\section{PROCESSING DIELECTRIC COMPOSITIONS}

The dielectric is printed with 200-mesh stainless steel screen to produce fired films which are 25 micrometers thick. To minimize pinholes in the dielectric the squeegee speed should not exceed about 7 centimeters per second (2.8 inches per second). In addition, the squeegee stroke should be adjusted so that the screen has lifted from the pattern area before the squeegee lifts for the return stroke.

The dielectric film is dried about 10 minutes at $120^{\circ} \mathrm{C}$ in an air atmosphere. Dielectric films are fired in the same type furnace as copper using the same $900^{\circ} \mathrm{C}$ firing profile shown in Figure 2.

Although addition of oxygen to the burnout section is not necessary, it is helpful under some conditions in removing organic vehicle components from the dielectric film to prevent blister formation in multilayer structures. Depending on the temperature in the burnout section, up to $600 \mathrm{ppm}$ oxygen may be added without significant oxidation of fired copper accompanying the dielectric.

Two layers of dielectric, each individually fired, are used between copper layers in the multilayer structures. 


\section{PROCESSING RESISTOR COMPOSITIONS}

Resistor compositions are printed with 325-mesh stainless steel screen over pre-fired 9922 copper terminations and are dried 10 minutes at $120^{\circ} \mathrm{C}$ in an air atmosphere. The dried films are about 25 micrometers thick. The resistor films are fired in the same type furnace (Figure 1) with the same firing profile as used for copper (Figure 2). The firing sensitivity over the range of peak firing temperatures from $875^{\circ} \mathrm{C}$ to $930^{\circ} \mathrm{C}$ is shown in Table I. Resistance change for the $10 \mathrm{~K}$ composition is $-2.5 \%$ per ${ }^{\circ} \mathrm{C}$. The change for other members of the series is between 1 and $2 \%$ per ${ }^{\circ} \mathrm{C}$.

The variation of resistivity and hot TCR with oxygen concentration in the burnout section is shown in Table II. Both resistivity and hot TCR are relatively insensitive to oxygen concentration in the range from 1 to 25 ppm which is within the practical limits of furnace control. Resistors may be fired with oxygen concentration in the burnout section of 6 to $8 \mathrm{ppm}$ which is the same as used for copper.

TABLE I

Resistor firing sensitivity.

\begin{tabular}{lc}
\hline Firing cycle time & - Standard \\
Peak temperature range & $-875-930^{\circ} \mathrm{C}$ \\
Resistor size & $-1 \mathrm{~mm} \times 1 \mathrm{~mm}$ \\
& \\
Resistivity & Sensitivity \\
$($ Ohms/square $)$ & $\left(\% /{ }^{\circ} \mathrm{C}\right)$ \\
& \\
20 & -1.0 \\
100 & +1.5 \\
$1 \mathrm{~K}$ & -2.0 \\
$10 \mathrm{~K}$ & -2.5 \\
\hline
\end{tabular}

TABLE II

Effect of oxygen in burnout section of $\mathrm{R}^{\mathrm{a}}$ and $\mathrm{HTCR}^{\mathrm{b}}$

Resistor size $-2.5 \mathrm{~mm} \times 5 \mathrm{~mm}$

\begin{tabular}{|c|c|c|c|c|c|}
\hline \multirow{2}{*}{\multicolumn{2}{|c|}{$\begin{array}{l}\text { Composition } \\
\text { (Ohms/square) }\end{array}$}} & \multicolumn{4}{|c|}{$\begin{array}{l}\text { Oxygen concentration (ppm) - burnout } \\
\text { section }\end{array}$} \\
\hline & & 1 & 25 & 50 & 100 \\
\hline \multirow{2}{*}{20} & $\mathbf{R}$ & 20 & 22 & 23 & 27 \\
\hline & HTCR & +73 & -42 & -43 & +22 \\
\hline \multirow{2}{*}{100} & $\mathbf{R}$ & 100 & 114 & 124 & 184 \\
\hline & HTCR & +37 & -60 & -47 & -25 \\
\hline \multirow{2}{*}{$1 \mathrm{~K}$} & R & $1.0 \mathrm{~K}$ & $1.3 \mathrm{~K}$ & $1.9 \mathrm{~K}$ & $6.9 \mathrm{~K}$ \\
\hline & HTCR & +115 & 0 & -120 & -1060 \\
\hline \multirow{2}{*}{$10 \mathrm{~K}$} & & $10 \mathrm{~K}$ & $6.1 \mathrm{~K}$ & $5.5 \mathrm{~K}$ & $5.3 \mathrm{~K}$ \\
\hline & HTCR & +17 & -50 & -83 & -280 \\
\hline
\end{tabular}

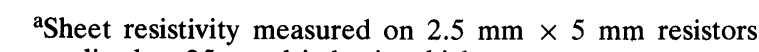
normalized to $25 \mu \mathrm{m}$ dried print thickness.

${ }^{b} 25^{\circ} \mathrm{C}$ to $125^{\circ} \mathrm{C}$.

\section{NITROGEN FURNACE DESIGN}

Commercial nitrogen furnaces suitable for firing copper, dielectric and resistor compositions are available from several vendors. Two typical designs are shown in Figure 1. The thick film nitrogen furnace must perform the same functions as an air furnace: remove organic vehicle components, sinter the functional phases and effect bonding to the substrate. The oxygen concentration must be maintained at a relatively low level in the hot sections of the furnace to avoid oxidation of copper. To prevent oxygen from entering the hot sections, purge chambers are provided at each end of the furnace. In addition, tight seals are necessary at flange joints and piping connections to prevent air from leaking into the furnace. Inadequate seals have been a source of serious processing problems.

The muffle construction may be stainless steel or quartz. Quartz provides a cleaner atmosphere, but it can be more difficult to obtain tight seals between a quartz muffle and a metal purge chamber. Furnaces have been provided with external nitrogen purges around the seals to solve that problem.

Furnaces may have natural convection vents or forced vents. Both have provided satisfactory service.

Nitrogen should be introduced to both the top and the bottom of the entrance purge chamber. Without the flow of nitrogen from beneath the belt, air can be trapped between the substrate and the floor of the purge chamber. The air can oxidize prefired copper on the underside of the substrate when it reaches the hot zones of the furnace.

\section{NITROGEN FURNACE AUXILIARY EQUIPMENT}

An oxygen analyzer, sample pump and sample lines are useful auxiliary equipment for monitoring the furnace atmosphere. The analyzer should have a range from 1 ppm to at least $1000 \mathrm{ppm}$. The sample pump should deliver about 1 liter per minute $\left(2 \mathrm{ft}^{3}\right.$ per hour). Sample lines near the hot sections of the furnace should be $1 / 4^{\prime \prime}$ stainless steel. A filter should be installed in the sample line between the furnace and the pump to prevent fouling the pump and analyzer with contaminants from the furnace atmosphere. A permanent sample line should be installed to the burnout section. In addition flexible $1 / 8^{\prime \prime}$ stainless steel sample lines are useful for inserting into the furnace at the ends to monitor the atmosphere anywhere along the belt. 


\section{NITROGEN FURNACE OPERATION}

It is important to balance the nitrogen flows and vent flows so that the pressure inside the furnace is above atmospheric. That will prevent air from being drawn into the furnace from the ends. Figure 3 shows practical nitrogen flow rates versus muffle width. Copper has been successfully fired with nitrogen flow rates shown at the bottom of the range. A range is shown because some furnaces may have higher muffles and some furnaces may be operated with larger vent flows which will require greater nitrogen flow to the furnace. Ten to twenty percent of the nitrogen should be introduced to each purge chamber and sixty to eighty percent should be added to the muffle.

The ends of the furnace should be protected from room air currents and should be enclosed as much as possible to prevent air from entering.

Typical commercial nitrogen has an oxygen specification of less than $10 \mathrm{ppm}$ and is usually supplied with 4 to $8 \mathrm{ppm}$ oxygen. It is not difficult to maintain the oxygen concentration below $15 \mathrm{ppm}$ in the hot sections of a furnace which does not have air leaks.

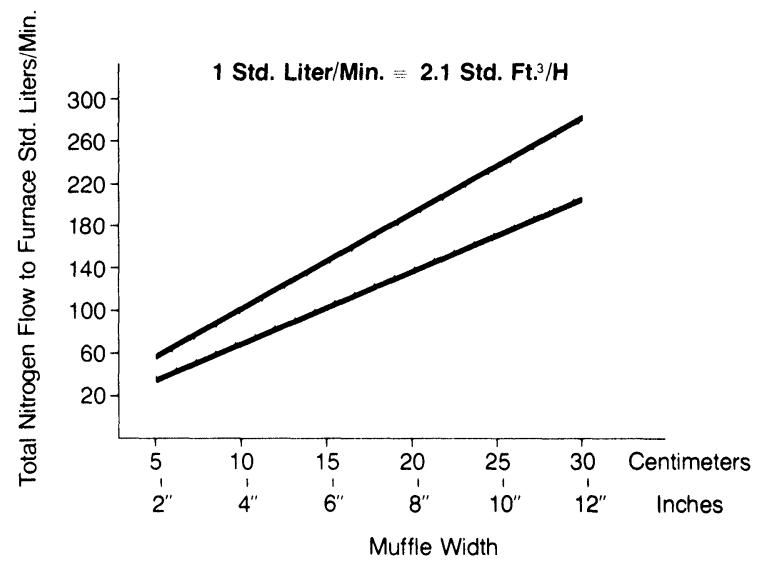

FIGURE 3 Nitrogen flow vs. muffle width.

\section{COPPER COMPOSITION PROPERTIES AND APPLICATIONS}

Copper compositions provide high adhesion conductors with resistivity values in the range of one to two milliohms per square per mil. Resistivity of copper is compared with precious metal thick film conductors in Figure 4. Copper is somewhat lower in resistivity than platinum-silver and gold conductors and is significantlý lower than palladium-silver and platinum-gold.

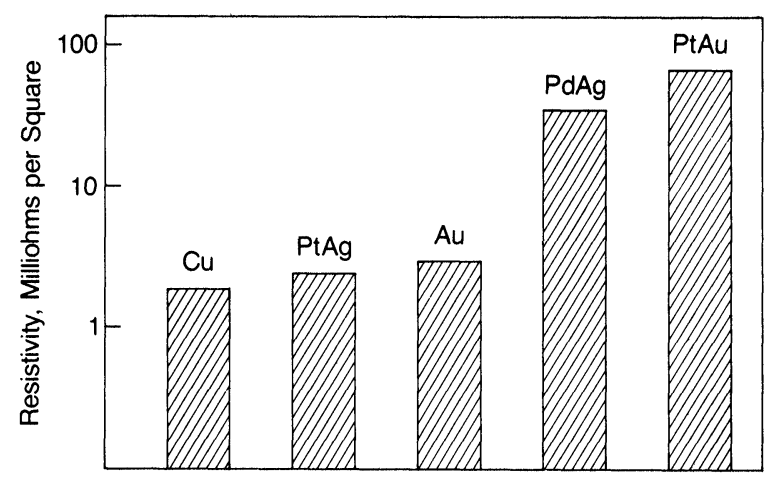

FIGURE 4 Resistivity of thick film copper vs. typical precious metal thick film conductors.

Thick film copper has been shown to produce low loss microwave circuits with a quality factor exceeding that obtained with thick film gold. ${ }^{1}$

Thick film copper forms excellent bonds to alumina and beryllia substrates. Wire peel adhesion ${ }^{2}$ values with $2 \mathrm{~mm}$ by $2 \mathrm{~mm}$ conductor pads range as high as 31 newtons ( 7 pounds) initially and 29 newtons (6.5 pounds) after aging 48 hours at $150^{\circ} \mathrm{C}$. Because of its high adhesion copper may be used in place of Mo-Mn metallizing.

Thick film copper conductors have outstanding solder leach resistance, a property which will permit extensive reworking of soldered components. Solder leach resistance is illustrated in Figure 5. After thirty immersions of ten seconds duration into $60 \mathrm{Sn} / 40 \mathrm{~Pb}$

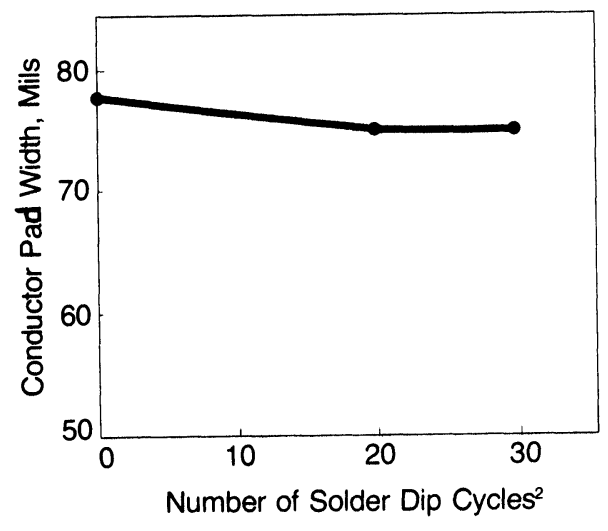

FIGURE 5 Solder leach resistance: copper conductor pad width vs. number of solder ${ }^{1}$ dips.

${ }^{1} 60 \mathrm{Sn} / 40 \mathrm{~Pb}$ heated at $225^{\circ} \mathrm{C}$.

${ }^{2}$ Each cycle consists of dip in mildly activated flux followed by 10 -second dip in solder followed by solvent cleaning. 
solder erosion of the edges of conductor pads was minimal.

When used with nitrogen-fireable dielectric composition 4175, copper may be used to make multilayer interconnect structures with up to four conductor levels.

\section{DIELECTRIC COMPOSITION PROPERTIES AND APPLICATIONS}

Dielectric 4175 forms a relatively dense film with the electrical properties shown in Table III. At one $\mathrm{kHz}$ the dielectric constant is in the range of 7 to 9 and the dissipation factor is less than 0.005 . Breakdown voltage is greater than $500 \mathrm{~V} / \mathrm{mil}$ and insulation resistance is greater than $1 \times 10^{12} \mathrm{ohms}$. When used with thick film copper, 4175 dielectric is useful for making multilayer interconnect circuits. Using a screen with $0.30 \mathrm{~mm} \mathrm{(12}$ mil) vias, 4175 dielectric will produce via prints which are 0.15 to $0.20 \mathrm{~mm}$ ( 6 to $8 \mathrm{mils}$ ) in size.

In addition, the dielectric may be used to protect copper from the environment and to define conductor areas for subsequent soldering.

TABLE III

Electrical properties 4175 dielectric

\begin{tabular}{ll} 
Dielectric Constant, K $(1 \mathrm{KHz})$ & $7-9$ \\
Dissipation factor $(1 \mathrm{KHz})$ & $\leqslant 0.005$ \\
Voltage breakdown, volts/mil & $\geqslant 500$ \\
Insulation resistance, ohms & $>1 \times 10^{12}$ \\
\hline
\end{tabular}

\section{RESISTOR COMPOSITION PROPERTIES AND APPLICATIONS}

Typical properties of the nitrogen-fireable resistors are shown in Table IV. Coefficient of variation $\dagger$ of resistivity (CV) ranges from 2.3 to $5.7 \%$. Temperature coefficient of resistance (TCR) ranges from $150 \mathrm{ppm}$ at 10 ohms per square to near zero at $10 \mathrm{~K}$ ohms per square. Both hot $\ddagger$ and cold $\ddagger$ TCR have approximately the same value for a given resistivity. In addition the TCR values are not affected by the geometry of the resistors so different size resistors have good tracking characteristics.

Resistivity change with refiring ranges from $+10 \%$ for the $10 \mathrm{ohm}$ per square resistors to $-11 \%$ for $10 \mathrm{~K}$ ohm per square resistors.

\footnotetext{
†Standard deviation divided by the mean.

‡Hot TCR temperature range is 25 to $125^{\circ} \mathrm{C}$; cold TCR temperature range is -55 to $25^{\circ} \mathrm{C}$.
}

TABLE IV

Typical nitrogen-fireable resistor properties.

Product numbers

\begin{tabular}{lrrrr} 
& 4239 & 4238 & 4237 & 4299 \\
\hline - Resistivity (Ohms/square) & 10 & 100 & $1 \mathrm{~K}$ & $10 \mathrm{~K}$ \\
$\begin{array}{l}\mathrm{CV}(\%) 1 \times 1 \mathrm{~mm} \text { resistors } \\
\text { - TCR }\left(\mathrm{ppm} /{ }^{\circ} \mathrm{C}\right)\end{array}$ & 2.3 & 5.7 & 3.8 & 2.7 \\
$\quad \mathrm{Hot}$ & +150 & +50 & +90 & +5 \\
$\quad$ Cold & +150 & +50 & +70 & -20 \\
- Resistivity change after & +10 & +2 & +9 & -11 \\
$\quad$ refire (\%) & & & & \\
\hline
\end{tabular}

Laser trim stability results are shown in Table V. The resistors were trimmed with a YAG laser at a rate of ten $\mathrm{mm}$ per second. Trim speeds as high as $75 \mathrm{~mm}$ per second have been used. The resistors were one millimeter in size and were trimmed with a plunge cut to about 1.5 times the original value. They were not encapsulated during subsequent tests.

Resistors were exposed to the following no-load test conditions for up to 800 hours: $25^{\circ} \mathrm{C}$ ambient, $150^{\circ} \mathrm{C}$ storage, $90 \%$ relative humidity at $40^{\circ} \mathrm{C}$ and 2 tensecond immersions into $62 \mathrm{Sn} / 36 \mathrm{~Pb} / 2 \mathrm{Ag}$ solder at $220^{\circ} \mathrm{C}$. In addition resistors were run with 31 watts per

TABLE V

Laser trim stability typical drift values.

Type laser - YAG

Trim speed $-10 \mathrm{~mm}$ per sec.

Type cut - plunge to 1.5 times resistance value

Resistor size $-1 \times 1 \mathrm{~mm}$

Not encapsulated

$\begin{array}{llll}4239 & 4238 & 4237 & 4299\end{array}$

\begin{tabular}{|c|c|c|c|c|}
\hline $\begin{array}{l}\text { Resistivity - Ohms/square } \\
24 \text { hrs. at } 25^{\circ} \mathrm{C}(\% \Delta \mathrm{R})\end{array}$ & $\begin{array}{l}10 \\
0.01\end{array}$ & $\begin{array}{l}100 \\
0.11\end{array}$ & $\begin{array}{l}1 \mathrm{~K} \\
0.08\end{array}$ & $\begin{array}{l}10 \mathrm{~K} \\
0.02\end{array}$ \\
\hline \multirow{2}{*}{$\begin{array}{l}\text { Solder dip, } 2-10 \text { sec. dips } \\
62 \mathrm{Sn} / 36 \mathrm{~Pb} / 2 \mathrm{Ag} \text { at } 220^{\circ} \mathrm{C} \\
(\% \Delta \mathrm{R})\end{array}$} & 0.03 & 0.02 & 0.04 & 0.02 \\
\hline & \multicolumn{3}{|c|}{$800 \mathrm{Hr}$. } & $300 \mathrm{Hr}$. \\
\hline $150^{\circ} \mathrm{C}$ storage, no load $(\% \Delta \mathrm{R})$ & 0.31 & 0.04 & 0.04 & 0.02 \\
\hline $\begin{array}{l}\text { Humidity }-40^{\circ} \mathrm{C} / 90 \% \mathrm{RH} \\
(\% \Delta \mathrm{R})\end{array}$ & 0.32 & 0.10 & 0.06 & 0.25 \\
\hline $\begin{array}{l}\text { Load life }-31 \mathrm{~W} / \mathrm{cm}^{2} \text { at } 70^{\circ} \mathrm{C} \\
1.5 \mathrm{hrs} \text {. on, } 0.5 \mathrm{hrs} \text {. off } \\
(\% \Delta \mathrm{R})\end{array}$ & 0.10 & 0.01 & -0.01 & $\begin{array}{l}-1.24^{\mathrm{a}} \\
-2.65^{\mathrm{b}}\end{array}$ \\
\hline
\end{tabular}

${ }^{\mathrm{a}} 15.5$ watts per square centimeter. Drift levels off after 100 hours.

b $_{31}$ watts per square centimeter. Drift levels off after 100 hours. 
$\mathrm{cm}^{2}$ (200 watts/in ${ }^{2}$ ) of power loading in a time cycle of 1.5 hours with power on and 0.5 hour with power off.

All compositions changed $0.1 \%$ or less at $25^{\circ} \mathrm{C}$ during the first 24 hours after trimming.

After 800 hours the average change in resistivity values for the 10,100 , and $1 \mathrm{~K}$ resistors was $0.3 \%$ or less during each of the tests. The change during most tests was less than $0.1 \%$. After 300 hours the $10 \mathrm{~K}$ resistors changed less than $0.3 \%$ during all tests except for load conditions. For load conditions of 15.5 watts per $\mathrm{cm}^{2}$ (100 watts/in $\left.{ }^{2}\right)$ the resistance change was $1.24 \%$; for 31 watts per $\mathrm{cm}^{2}$ (200 watts/in ${ }^{2}$ ) loading the change was $-2.65 \%$. The change occurred during the first 100 hours under load with little change after 100 hours.

Resistivity is relatively independant of the length of the resistor as shown in Figure 6.

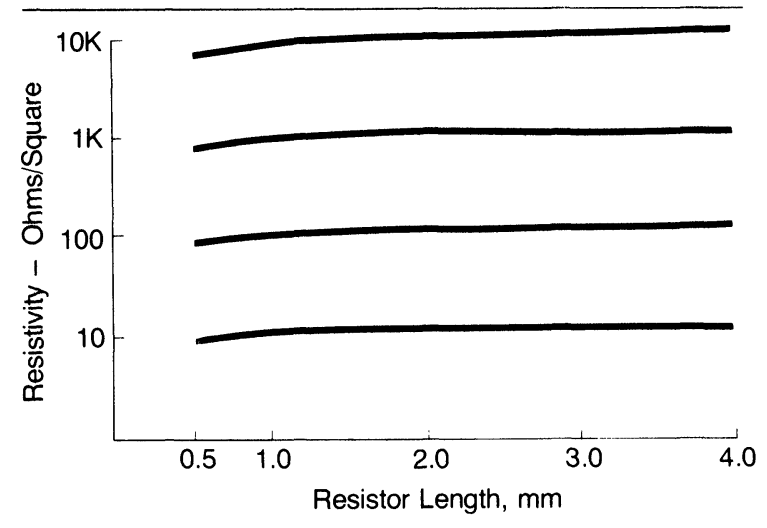

FIGURE 6 Resistivity vs. length.
These resistor compositions have characteristics which make them particularly useful for resistor networks and hybrid microcircuits. In addition they are compatible with nitrogen-fireable dielectric 4175 and may be applied on the top dielectric layer of multilayer structures.

\section{CONCLUSIONS}

A copper materials system has been developed with high adhesion low resistivity conductors, a dense low $\mathrm{K}$ dielectric and resistor compositions from 10 to $10 \mathrm{~K}$ ohms per square with characteristics similar to the BIROX ${ }^{\circledR} 1600$ series.

The compositions are printed and dried using the same equipment and procedures as used for precious metal thick film compositions.

The copper materials system compositions are fired in nitrogen furnaces which are commercially available using commercial nitrogen. Care must be taken to prevent air from leaking into the hot sections of the furnace to avoid oxidizing the copper.

\section{REFERENCES}

1. J. P. Ramy et al., "Optimization of the Thick- and ThinFilm Technologies for Micro-wave Circuits on Alumina and Fused Silica Substrates," IEEE Transactions on Microwave Theory and Techniques, Vol. MTT-26, 814820 (October, 1978).

2. "Method of Test for Wire Peel Adhesion of Soldered Thick Film Conductors to Ceramic Substrates," E. I. du Pont de Nemours \& Co., Technical Bulletin A-74672 (March, 1971). 

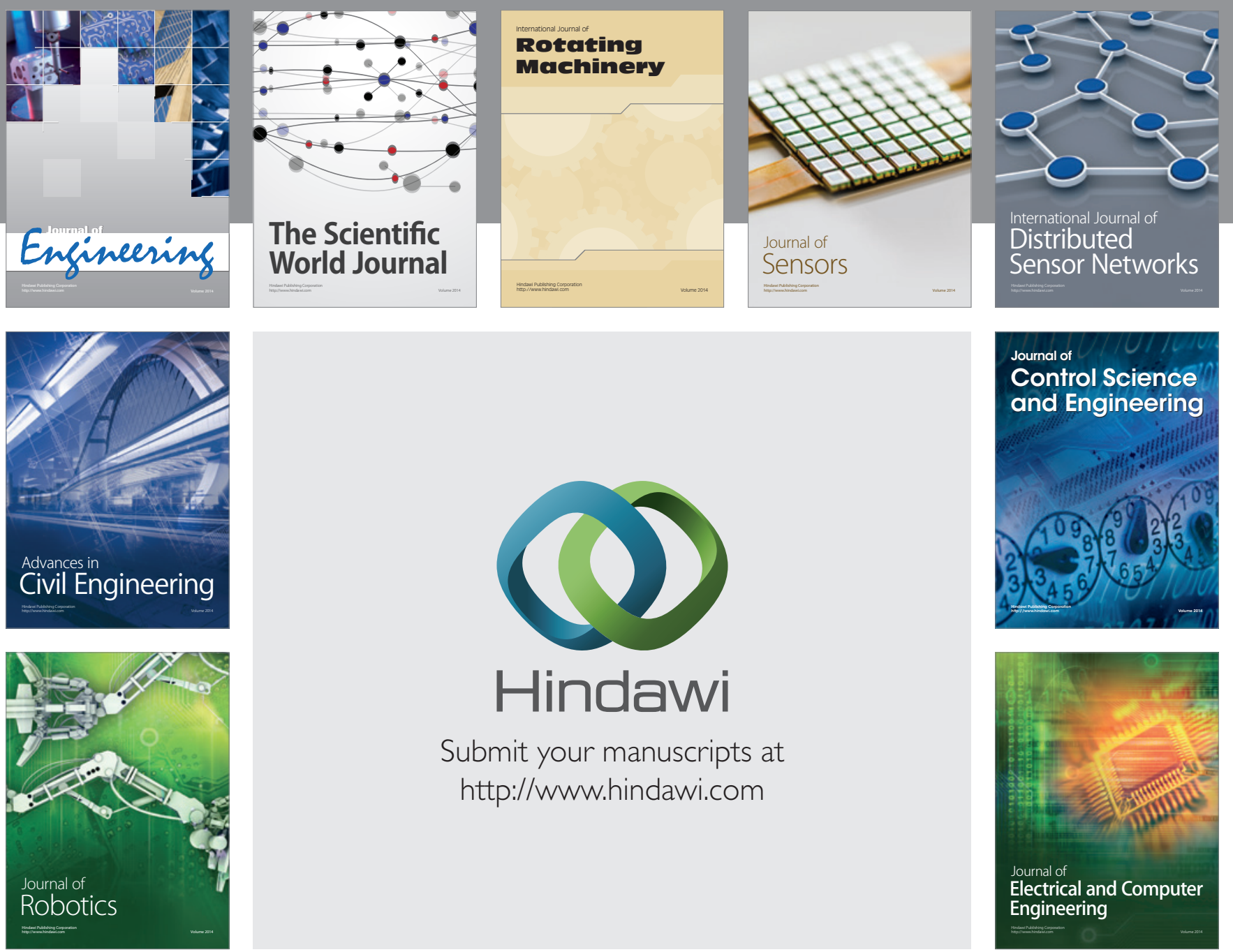

Submit your manuscripts at

http://www.hindawi.com
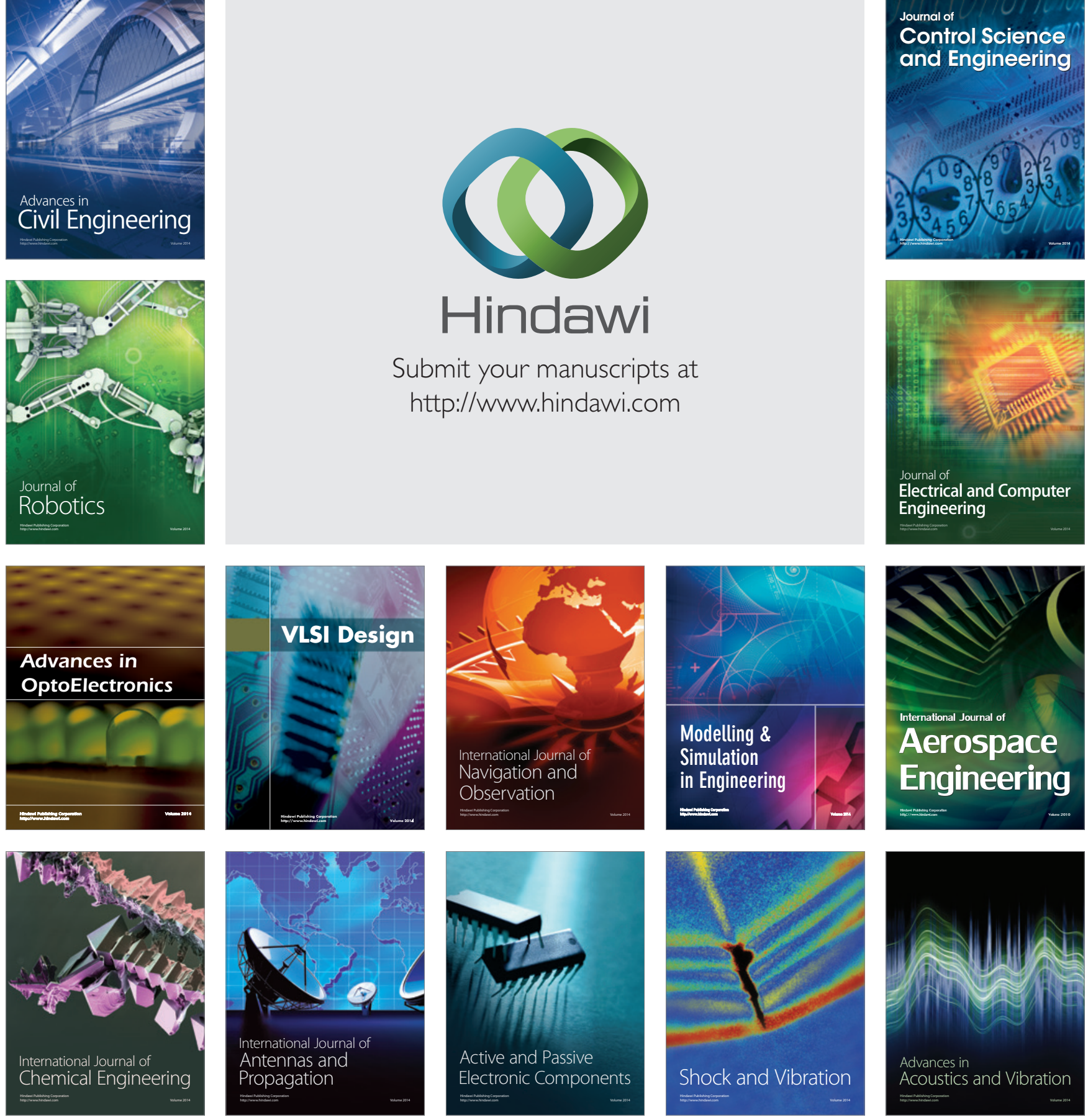